\title{
German Idealism, Classical Pragmatism, and Kant's Third Critique
}

\author{
Sebastian Gardner
}

German Idealism and Classical Pragmatism share Kantian origins. An obvious way in which one may seek to characterize their differences is in terms of Kant's distinction of the constitutive and regulative. Classical Pragmatism, it is plausible to suggest, retains the Kantian regulative and either drops the constitutive or subordinates it to the regulative, while German Idealism holds fast to the constitutive, massively enlarging its scope and absorbing into it (among other things) all of Kant's 'merely' regulative structure; whence the metaphysicality of German Idealism and the postmetaphysicality, or tendency thereto, of Classical Pragmatism.

Matters are of course not quite so simple - in a moment I will point out some complications - but this construal of the historical narrative has explanatory value and textual foundations. It is not hard to see that engagement with Kant's concept of the regulative is virtually unavoidable for any post-Kantian development that seeks, as do German Idealism and Classical Pragmatism, to overhaul Kant's meta-philosophical position: if a less equivocal view of our knowledge situation than Kant's is to be arrived at, then the notion of a 'merely regulative' employment of ideas, sharply disjoined from a constitutive employment of concepts, will need to be revisited and continuity restored in one way or another. Thus, in so far as Kant is regarded not only as providing resources for each development but also, in addition, as himself failing to settle the problems that arise for his dual status account of the principles of cognition and so as leaving a tension that stands in need of resolution, the double derivation of two such different standpoints from a single source is rendered historically intelligible.

At the textual level it is plain that Kant's notion of regulativity has considerable importance for Peirce and that it appears by contrast to hold relatively little interest for the German Idealists. What Kant calls a regulative principle Peirce describes as 'an intellectual hope' (CP 1.405) and it is against this background - the hope of guessing correctly, and therewith of regulating our future conduct rationally - that he sets abduction (CP 2.270). ${ }^{1}$ The three principles of systematicity in empirical cognition laid down in Kant's Critique of Pure Reason - inclusive of the law of continuity, of high importance for Peirce - are endorsed as 'regulative laws of logic' (CP 1.449, CP 3.215). Peirce's doctrine of synechism too qualifies as a regulative principle of logic, prescribing what sort of hypotheses are fit to be entertained (CP 6.173). ${ }^{2}$ In the most general sense, Peirce affirms, regulativity constitutes the very nature of (genuinely tryadic) thought (CP 6.324). James, 
though seldom referring explicitly to Kant as an intellectual source in the manner of Peirce, expands on Peirce's conception of regulative function, to which his discussions of truth are clearly indebted. ${ }^{3}$

By contrast, Schelling's references to the regulative are few and far between ${ }^{4}$ and his Naturphilosophie is staked on the idea that the regulative construal of teleology provides no adequate basis for thought about Nature. Schelling contends that a unitary account of the inorganic and organic realms can be given - they must be regarded as reciprocally related to one another, as mutually explanatory, if we are to have insight into the true nature of each ${ }^{5}$ - and accordingly rejects Kant's epistemic dualism, the effect of which is to split Nature down the middle. What Kant calls the problem of teleological judgement and believes requires a special solution, Schelling treats as simply a further case of the wholly general epistemological problem of explaining how a conceptual form can be intuited as enjoying an actual independent existence in things outside the subject; nothing is gained by reclassifying teleology as merely regulative. ${ }^{6}$ For Hegel, the resort to regulativity marks Kant's failure to develop out of reason the 'speculative, truly infinite Concept'. Reason in Kant, Hegel tells us, 'becomes the familiar, wholly formal, merely regulative unity of the systematic employment of the understanding'. ${ }^{7}$ Kant was right, Hegel says, to confine reason to merely regulative use but only because he had denied it any content of its own. ${ }^{8}$ In Hegel's early Jena essays the idea that resort to assigning reason infinite tasks signifies philosophical deficiency is used to differentiate true, speculative philosophy from mere subjective idealism. More interesting in Hegel's view is regulativity's successor notion, reflective judgement, but it too expresses a limitation, namely Kant's false 'external' view of the relation of reflection to its object. ${ }^{9}$

The alignment has however, as said, its complications. Even when painting with the broadest of brushes, and holding aside recent pragmatism-influenced reconstructions, German Idealism cannot be characterized in its entirety as uniformly and unequivocally constitutive-ratherthan-regulative. Recently Frederick Beiser has argued that the central claims of the Wissenschaftslehre must be regarded as regulative on the grounds that, if Fichte is to avoid contradiction, then the claim that there is an absolute I must be understood as identifying an ideal for action, not an existing entity. ${ }^{10}$ However, Fichte does not appeal explicitly to the concept of the regulative in defining the nature of the Wissenschaftslehre, ${ }^{11}$ and he appears to regard its metaphilosophical status as extremely problematic, an issue which is perhaps never quite settled to his satisfaction. ${ }^{12}$ The exegetical issue here is obviously a difficult one, but even if Beiser is right about the logic of Fichte's position, it could not be maintained (nor does Beiser do so) that the Kantian concept of the regulative stands at the methodological heart of the Wissenschaftslehre or that it provides a golden key to Fichte's meta-philosophical departures from Kant; more plausibly this role is played by Kant's non-regulative Fact of Reason. ${ }^{13}$ It is therefore important to recognize that when the differences of Fichte from early Schelling are glossed, as is commonly done, in terms of the 
constitutive/regulative distinction - Fichte regulative, Schelling constitutive - this begs further questions and does not fully illuminate what distinguishes their standpoints. A fuller treatment of this topic would, I believe, require investigation of the role played by the concept of a postulate in Fichte and his successors. ${ }^{14}$

The alignment of Classical Pragmatism with regulativity also has some rough edges. James' regulativism is fairly clear: 'The pragmatic method starts from the postulate that there is no difference of truth that doesn't make a difference somewhere [...] The principle of pure experience is also a methodological postulate. ${ }^{15}$ The pragmatic conception of truth is presented by James as agreeing with experience, as consorting with the facts concerning the course of human opinion and the character of our psychology, but he does not stake it on any independent prior theoretical claim or take it to imply of itself any characterization of objects: the radical empiricist insight that felt relations belong to the content of experience undercuts the motivation for several alternatives to pragmatism, but it does not entail the pragmatist maxim, and the maxim itself specifies only a method or procedure, namely of apportioning epistemic value (and rational virtue more generally) in accordance with the (interest-relative) consequences that ensue when we, as James puts it, dip back into the particulars of experience under a thought's guidance. ${ }^{16}$ Elucidating the regulative rationality of the pragmatic principle is for James ultimately a matter of indicating the emptiness and arbitrariness of the alternatives. Peirce's outlook is less straightforward. In the early 'The Fixation of Belief' (1877) a strong hint of transcendentalism surrounds Peirce's treatment of the ('absolutely essential', 'necessarily taken for granted') habits of mind or 'guiding principles' of inference and the concepts correlated with them (CP 5.367-369). ${ }^{17}$ But by the time of the Monist papers Peirce has come to reject naked presupposition: the philosophical invocation of postulates, according to 'The Doctrine of Necessity Examined' (1892), amounts to nothing more than the expression of an ungrounded hope of truth. The only things that can be meaningfully postulated, Peirce says, are material facts ultimately capable of presenting themselves in experience; hypothesis and provisional inference take the place of postulation (CP 6.39-43). It follows that regulative principles cannot be established by purely transcendental means, ${ }^{18}$ but not that Peirce abjures regulativity: Peirce's strategy is to treat factual status and inherent regulative function as constitutively interconnected rather than mutually exclusive alternatives, erasing Kant's sharp distinction of truth from validity qua methodological imperative. Thus in 'A Guess at the Riddle' (1887-88) Peirce is able to treat the 'rule of hope' - the meta-rule that we are to proceed on the basis that any given general fact can be made intelligible - both as sanctioned quasi-transcendentally by the self-stultification of thought which would be involved in its rejection, and as itself susceptible to and requiring the kind of grounding which his scientific metaphysics aims to provide (CP 1.404- 
406). At the level where James asserts a self-supporting methodological postulate, Peirce demands metaphysical underwriting, an explanation of 'Law or regularity itself' (CP 1.406). ${ }^{19}$

We find ourselves confronted with a host of interpretative and systematic questions, of which not the least important concerns the grounds and justification of each of the two developments out of Kant. It is this question which I wish to pursue in the main part of this paper. What I will try to show is that the the original parting of ways of German Idealism and Classical Pragmatism, understood systematically and to some extent also historically, can be assigned a definite locale in Kant's Critique of the Power of Judgement. The Third Critique opens up a perspective on Nature that Kant himself does not pursue but on which Schelling seizes. At its centre stands a new way of thinking about regulative principles.

We may begin by taking up the basic question of how Kant understands regulativity. According to the standard picture, Kant regards regulative principles as having exclusively heuristic or methodological value, i.e. as ones to which no kind of truth can be ascribed: to the extent that ideas employed regulatively have reference, it is to the objects of the understanding, while regulative principles themselves express no properties, neither intrinsic nor relational, of those objects; they are merely conceptual devices that need to be employed if the properties of empirical objects are to be determined in full. Thus Norman Kemp Smith: 'Kant regarded the Ideas of Reason as having a purely and exclusively regulative function, and consequently as exhausting their inherent meaning in their empirical reference. ${ }^{20}$ Robert Butts: Kant's regulative concepts 'have had their Leibnizian metaphysical content drained away, leaving a merely methodological framework'; 'Leibniz's world of perfectly oriented noumenal reals becomes for Kant a methodological fiat'; 'reason bears no relationship to objects, but only to attempts to understand'. ${ }^{21}$ More recently Susan Neiman has offered an account of Kant's reconception of reason, as she calls it, which finds in reason's regulative employment the unifying meta-principle of his philosophy as a whole. Regulative principles as Neiman understands them are not assertions or items of knowledge but sheer demands. They cannot even be described as assumptions, since they 'do not tell us about the world at all but are purely subjective, concerning how we are to behave': ${ }^{22}$

Regulative principles are not hypotheses because their concern is not with objective reality but with subjective determination - not with what is but with what ought to be. Constitutive principles tells us what the world is like; they must, therefore, be grounded in an object. Regulative principles concern our needs and capacities and are grounded in the same. ${ }^{23}$ 
Many formulations in this vein can be found in the commentaries. The standard problems and points of discussion concerning regulative principles include the seeming ambiguity in the First Critique as to whether regulative principles are logical or transcendental, and hence in need of a deduction; and the question of whether Kant's association of systematic empirical knowledge with the transcendental ideas is licit - the puzzle being why exactly the general imperatival stimulus to the understanding to keep hard at work should implicate the ideas of God and the soul. In addition there is the problem of subjectivism - the fact that Kant appears to simply lay it down that we have a faculty which makes certain demands, on no independent ground, that our representations should exhibit a certain form, and which conditions our cognition accordingly; exposing Kant to Jacobi's objection that Critical philosophy annihilates all relation to objectivity for the sake of a mere selfrelation, reducing our highest ideas to 'Fictionen'24 - a view of the logical terminus of Kantianism shared by Hans Vaihinger, who joins a general theory of explanatory concepts as 'fictions' with a biologically conditioned account of the function served by thought's regulation-by-fiction. ${ }^{25}$

In addition to issues arising from the exposition of regulativity in the First Critique, what is also well recognized and has been widely discussed in recent times, is the continuity of Kant's earlier conception of regulativity with the Third Critique's account of reflective judgement, which loosens the connection of regulativity with the transcendental ideas, and recasts its principle as that of purposiveness, now housed in the faculty of judgement. ${ }^{26}$

Kant continues in the Third Critique to insist on the subjectivity of regulative principles. ${ }^{27}$ In the Dialectic of Teleological Judgement the principle of reflective judgement is described as 'a merely subjective principle for the purposive use of our cognitive faculties' $(\S 70,385),{ }^{28}$ 'a reflecting (on a subjective ground)' (\$70,388): 'reason cannot judge at all objectively (synthetically), and by itself it contains, as theoretical reason, absolutely no constitutive principles, but only regulative ones' $(\$ 76,401)$; 'judgements made in this way [viz. 'in accordance with the subjective conditions for the exercise of our faculties'] cannot be constitutive principles determining how the object is constituted [... but] there can still be regulative principles, immanent and secure in their use and appropriate for the human point of view' $(\$ 76,403)$.

But what is also the case is that Kant has provided sufficient materials for interpreting this subjectivity, not in the manner of the First Critique and in accordance with the standard picture of regulativity, but as incorporating a new kind of objectivity, hitherto absent from the Critical philosophy. The two elements in the Third Critique that combine to yield a new grade of 'realist' objectivity are the account of nature's systematicity, and the discussion of an intuitive understanding in sections $\S \S 76-77$. I will take these in turn. 
1. Kant returns in the Third Critique to the topic, treated earlier in the Appendix to the Transcendental Dialectic, of nature's systematicity considered as a condition of scientific knowledge of the natural order, and gives a fuller account of the basis of the relevant principles, the 'maxims of reason', which instruct us to regard nature as having systematic form. It is clear why systematicity in nature should reappear on Kant's agenda. The Third Critique is concerned, as one of its two main new fields of enquiry, with teleology. To think that the order of nature lends itself to systematic cognition is not to think that it is an order of ends, or that any entity within nature is explained teleologically, but it is to take a step in that direction. Both orders exceed the mandate of the understanding as defined in the Analytic of the First Critique, and they do so in the same way: teleological order, as Kant analyses it, consists in the determination of the parts of a composite entity by the concept of the whole. So they have it in common that they both employ concepts of totality - the totality of nature grasped in a single scientific system, and the totality of an entity as the ground of its internal form.

Kant does not advertise the Third Critique's treatment of empirical systematicity as departing from his earlier view, but it is clear nonetheless that much has been rethought and that on at least some points his position has changed. In the first instance, the assumption of the systematicity of nature is reformulated and restated in more general terms that connect it with the topic of teleology in the following striking way: To assume that there is in nature an order accessible to scientific systematization is to assume, as Kant now puts it, that nature is purposive for our power of cognition. Second, the assumption of systematicity in nature, originally ascribed to reason, is reattributed in the Third Critique to the faculty of judgement in its 'reflective' capacity, whereby it searches for universals under which to bring given particulars, instead of subsuming particulars under given universals ('determinative' judgement). This in itself might not amount to much, Kantian faculty individuation being arguably a somewhat artificial business, but it is connected to another change which is clearly of great importance. For Kant now claims that the assumption of nature's systematicity is required for empirical concept formation as such, thereby making it a condition for empirical cognition überhaupt, whereas previously it had been required only for the employment of the understanding in its fullest extent. Formerly it was set down as a condition for a maximum of cognition, now it is required for any cognition at all: ${ }^{29}$

The principle of reflection on given objects of nature is that for all things in nature empirically determinate concepts can be found, which is to say the same as that in all of its products one can always presuppose a form that is possible for general laws cognizable by us. For if we could not presuppose this and did not ground our treatment of empirical representations on this principle, then all reflection would become arbitrary and blind, and 
hence would be undertaken without any well-grounded expectation of its agreement with nature.

With regard to the general concepts of nature, under which a concept of experience (without specific empirical determination) is first possible at all, reflection already has its directions in [...] the understanding, and the power of judgment requires no special principle of reflection $[\ldots]$

But for those concepts which must first of all be found for given empirical intuitions, and which presuppose a particular law of nature, in accordance with which alone particular experience is possible, the power of judgment requires a special and at the same time transcendental principle for its reflection [...] For it is open to question how one could hope to arrive at empirical concepts of that which is common to the different natural forms through the comparison of perceptions, if, on account of the great diversity of its empirical laws, nature (as it is quite possible to think) has imposed on these natural forms such a great diversity that all or at least most comparison would be useless for producing consensus and a hierarchical order of species and genera under it. All comparison of empirical representations [... presupposes] that even with regard to its empirical laws nature has observed a certain economy suitable to our power of judgment and a uniformity that we can grasp, and this presupposition, as an a priori principle of the power of judgment, must precede all comparison. (First Introduction, Sect. V, 20:211-213) ${ }^{30}$

These changes have been well discussed, ${ }^{31}$ and while there is disagreement about the role of the new discussion of systematicity in relation to our knowledge of empirical causal laws (as opposed to our knowledge of the a priori causal principle), and thus in relation to Kant's solution to the problem of induction and reply to Hume, there is general agreement on the success of Kant's argument for making systematicity in nature a condition of empirical cognition as such. Kant's point after all is simply that, if any empirical concepts are to be formed, then it must be assumed that the properties exhibited by nature are to some degree uniform and repeated across sets of particulars over which we can generalize; nature must furnish 'projectable' predicates. This seems hard to contest, and if it is a point that Hume missed, or attached no importance to, then it is because he was willing to allow knowledge in whole to rest on bare empirical contingency.

2. We turn next to sections $\$ \S 76-77$ of the Dialectic of Teleological Judgement, in which Kant discusses the differences between our discursive mode of cognition, and a non-discursive mode of cognition of which we can at least form a concept, whatever may be said concerning its existence or real extra-logical possibility. 
In $§ 76$ Kant explains that for this latter mode of cognition - specified as one in which the two 'entirely heterogeneous' powers of concept-applying understanding and object-intuiting sensibility are not separated but rather are one and the same, i.e., as cognition in which understanding is intuitive - the distinction of the actual from the possible, which is 'absolutely necessary for the human understanding', would not exist:

It is absolutely necessary for the human understanding to distinguish between the possibility and the actuality of things. The reason for this lies in the subject and the nature of its cognitive faculties $[. .$.$] if our understanding were intuitive, it would have no objects except$ what is actual. $(\$ 76,5: 401-402)$

And in $\$ 77$ he explains that non-discursive cognition - which Kant now re-specifies as cognition which proceeds from the universal to the particular - would not encounter the problem that makes teleological judgement necessary for us:

Our understanding, namely, has the property that in its cognition, e.g., of the cause of a product, it must go from the analytical universal (of concepts) to the particular (of the given empirical intuition) [...] Now, however, we can also conceive of an understanding which, since it is not discursive like ours but is intuitive, goes from the synthetically universal (of the intuition of a whole as such) to the particular, i.e., from the whole to the parts. $(\S 77,5: 407)$

The key points for present purposes are these.

(a) In $\S 76$, following out the implications of the fact that the modal distinctions necessary for us have no meaning for a non-discursive intellect, Kant tells us that we should think of the moral law, the principle that governs practical reason, in the following terms. An action that is morally necessary 'can [must] be regarded [at the same time] physically as entirely contingent (i.e. what necessarily should happen often does not)'. For this reason the moral law must be represented imperativally, as a command: 'reason expresses th[e practical] necessity not through a be [Seyn] (happening) but through a should-be [Seyn-Sollen]' (5:403). The concept which corresponds to the Sollen of the moral imperative is the concept of an (intelligible) world in which all is as it should be. This is of course for us 'a transcendent concept', 'not serviceable for any constitutive principle for determining an object and its objective validity', but 'it can serve as a universal regulative principle' for beings in the sensible world (5:404). 
The issue of the arguable moral need for the intelligible to have reality qua ground of transcendental freedom is not of concern here: the important point is just that we are to regard one and the same content, or state of affairs, as capable of figuring in two possible modes, either that of Seyn (for non-discursive cognition) or that of Seyn-Sollen (for discursive cognition).

(b) The second key development is Kant's exposition - beginning in the final paragraph of $\$ 76$ - of the idea of opposite but complementary directions of cognition. The cognition of a nondiscursive 'intuitive understanding' proceeds top-down, extracting particulars from universals, while our discursive understanding, presented with particulars in intuition and searching for concepts under which to bring them, proceeds bottom-up. Intuitive understanding possesses synthetic universals ('the synthetically universal' or 'intuition of the whole as such'), while our concepts are mere 'analytical universals'.

It is important for what will come later to note that the idea of opposed directions of cognition, as Kant explains it, involves no distinction of kinds of objects. ${ }^{32}$ The association of intuitive understanding with cognition of things in themselves, and of discursive understanding with cognition of appearances, is a separate matter; and if the objects of an intuitive intellect and those of a discursive intellect are necessarily of a different kind, this is compatible with their being taken to correspond or even to be ultimately identical.

My suggestion is that the combination of Kant's commitment to systematicity in nature with his account of modes of cognition in $\S \S 76-77$ takes us much of the way to Schelling's unequivocally constitutive view of nature as a systematic teleological order, in which Kant's view of nature is fused with Spinoza and 'mere' regulativity is overtaken:

As long as we only know the totality of objects as the sum total of all being, this totality is a mere world, that is, a mere product for us [...] Insofar as we regard the totality of objects not merely as a product, but at the same time necessarily as productive, it becomes Nature for us, and this identity of the product and the productivity, and this alone, is implied by the idea of Nature, even in the ordinary use of language. Nature as a mere product (natura naturata) we call Nature as object (with this alone all empiricism deals). Nature as productivity (natura naturans) we call Nature as subject (with this alone all [naturphilosophisch] theory deals) [...] There has long been a theory that the magnetic, electric, chemical, and, finally, even the organic phenomena, are interwoven into one great interdependent whole. This must be established [...] Nature [...] viewed as a whole [...] is absolutely organic [... T] he difference between organic and inorganic nature is only in Nature as object [...] Nature as originally productive soars above both. ${ }^{33}$ 
I will present the argument bridging the Third Critique and Schelling's Naturphilosophie formally in a series of steps.

(1) We are committed by our claim to empirical knowledge to the systematicity of nature qua object of our cognition.

This is simply the claim of Kant's discussed earlier.

(2) The systematicity of nature qua our mode of cognition is equivalent to the existence of nature qua object of intuitive understanding. (By §77.)

This follows directly from $§ 77$. What it is for the objects of our experience to be given to us as having systematic form is the same as what it is for an intuitive understanding to cognize objects, in the sense that, though the directions of cognition are opposed, the structure cognized - the order revealed in cognition - is one and the same.

Thus far, systematic discursive cognition, and the cognition of an intuitive understanding, are taken to be symmetrical, neither having any kind of precedence over the other; what is gained for Kant by introducing the notion of intuitive understanding in this context is simply to bring out their correspondence. But in the next two steps this relation becomes asymmetrical.

(3) The systematic form of nature cannot be regarded as deriving from our mode of cognition, because it cannot be understood as a product of our acts of synthesis. (By §77.)

All that our cognition can do is synthesize, i.e., combine what is originally un-unified. Again this comes from $\S 77$, though it goes back to the claim in $\S 15$ of the Transcendental Deduction in the First Critique ('On the possibility a combination in general') that 'the combination (conjunctio) of a manifold in general can never come to us through the senses' and 'is an act of the spontaneity of the power of representation': 'we can represent nothing as combined in the object without having previously combined it ourselves [...] among all representations combination is the only one that is not given through objects but can be executed only by the subject itself' (B130). ${ }^{34}$

(4) The systematic form of nature must therefore be thought to have its source in the existence of nature qua object of intuitive understanding. (From (3), by elimination.) 
From the negative claim of (3) we have now advanced to the positive claim that an intuitive understanding must be regarded as the ground of the systematic form of nature: It is necessary that we be able to assemble parts into a whole, but we can do so only if the parts derive from a whole our movement from parts-to-whole requires that there be a prior whole; and if this prior whole is not of our making, then it must come to us from without and exist independently. The equivalence of (2) has therefore become an asymmetry: the cognition of an intuitive understanding and our systematic discursive cognition of nature are now related as ground and consequence.

This inference assumes of course that the systematic form of nature must (be thought to) have a source, and this might be challenged. ${ }^{35}$ Thus the observation is sometimes made by commentators that Kant may seem, in elevating systematicity of nature to a transcendental principle, to be assuming that we need the systematicity of future experience to be guaranteed, and that the warrant for this assumption is not obvious (as the objection may be put: all we need do is get to work and see what ensues). This objection leads off into broader issues, but all that need be said about it here is that, if it is true that Kant ought not to be aiming to secure a strong modality for the assumption of nature's systematicity, then his whole treatment of this issue in the Third Critique is ill-conceived (it would follow, in fact, that he ought to have stuck to the the First Critique's unelaborated assumption of transcendental affinity as a ground for systematic order in nature ${ }^{36}$ ).

(5) The regulative principles which express our commitment to nature's systematicity and teleological order, though imperatival in their logical form, have the value of theoretical cognitions (objective reality). (By §76.)

The thought here is simply that our commitment to there being systematicity in nature extends beyond mere methodology. What specifically licenses us to think in terms of 'true imperatives' is the structure that Kant describes in $\S 76$ : the conception of a parallelism of domains across the is/ought distinction, of Sollen as a mirror-image of Seyn. ${ }^{37}$ It is true that the import or cash value (what Peirce would call 'the rational purport for the conduct of life') of the idea that nature is in itself systematically articulated is that we can and must follow certain formally constrained routes of synthesis: the idea projects a future series of syntheses, and for that reason we express it regulatively. But the idea itself does not consist in or reduce to an epistemic disposition. Rather the systematicity of nature is given to us non-objectually, as (or in) a task: it is not itself a task but rather the task's ground and object. ${ }^{38}$ This is of course a stronger conception of regulativity than that which, I said earlier, is standardly attributed to Kant.

This sort of double consideration of principles, whereby a principle allows itself to be viewed as regulative from one angle and as constitutive from another, surfaces in an early essay of 
Schelling's: 'What is absolute harmony for the absolute I is for the finite I elicited harmony, and the principle of unity is for the former the constitutive principle of immanent unity but for the latter only a regulative principle of objective unity which ought to become immanent. ${ }^{39}$

It is helpful to note that what we now have, in the regulative principles determining nature's systematicity, are mirror-images on the side of theoretical reason of the postulates of practical reason. The practical postulates are theoretical in form but grounded in practical cognition - truths that arise from an imperative. The regulative principles of nature's systematicity are practical in form but grounded in theoretical cognition - imperatives with true content. Practical law requires the postulates, theoretical claims which are derived from a determination of the will. Theoretical cognition requires the principles of nature's systematicity, theoretical claims which are recast as imperatives. It is a proper consequence of the unificatory project of the Third Critique that the distinction of directions of fit which we employ unproblematically at the empirical level - mind-toworld in the case of belief, world-to-mind in the case of desire - should begin, at the transcendental level, to dissolve. The idea of a doxastic state intermediate between belief and desire - a state which cannot be exhibited empirically, or which is only hinted at in attitudes of hope and faith - hovers over the Third Critique without ever coming to the surface (or doing so only in the, famously ambiguous, moral theology).

(6) To conceive nature as an object of intuitive understanding is to conceive nature as, fundamentally and intrinsically, an organism. (By §76.)

An intuitive understanding is a mode of cognition in which the function of presenting objects is performed by the intellect, thus a mode of cognition in which the distinction of intuition and conceptualization is sublated, thus one in which (as per §76) cognition and creation of objects are indistinguishable. To think of nature as the object of an intuitive understanding is therefore at the same time to think of it as created by the cognition of it, i.e., as an object which is caused by a concept (a synthetical universal) and in which the parts are effects of the whole; which is Kant's definition of the non-relative, internal purposiveness attributed to natural ends ( $\$ 63)$.

This is the step that Schelling takes but Kant does not. Of course, in so far as the claim that Nature is fundamentally and intrinsically an organism is formulated in the terms of the earlier quotation from Schelling, it involves additional elements - a distinction of product and productivity, and notion of self-production. These need not be gone into here. The present point is just that Schelling's conversion of Kant's philosophy of nature into a Spinozistic absolute idealism, for all that it goes beyond Kant, is not short of Kantian motivation. 
Let me now go back over the argument and add some comments in an attempt to clarify the key steps.

When we put together the two ideas which Kant tells us we must form when we reflect on the contrast of our cognition with non-discursive cognition - the idea of an identity of Is and Ought, and of two opposed but complementary directions of cognition - we arrive at the idea that discursive cognition is a transformation of the intuitive understanding grounded in a division of cognitive functions, and that intuitive and discursive intellects can be regarded in a complex way as isomorphic. Our employment of the principle of nature's systematicity, and the indispensability of that assumption, are accordingly understood in terms of our cognition's having the inverse form of that of an intuitive intellect, meaning that what we do when we proceed in accordance with regulative principles, is to seek to bring our cognition into conformity with that of an intuitive intellect (an infinite approximation). The 'ought' of our regulative principles is for the intuitive intellect an 'is', and the path of our cognition terminates at the point where intuitive understanding begins.

The characterization of our cognition as the inverse of an intuitive understanding gives regulativity an objective significance that it lacked previously: we stand in a different relation to the Third Critique's characterization of our cognition as the inverse of an intuitive understanding, from the relation in which we stood to the First Critique's notion, in the chapter on phenomena and noumena, of non-sensible intuition. The concept of intellectual intuition plays no positive role in the account of empirical knowledge in the Transcendental Aesthetic and Transcendental Analytic, where it provides merely a limiting concept, a Grenzbegriff, and to each of the two modes of cognition considered, a discrete set of objects - phenomena and noumena, about whose relation there is nothing determinate to be thought - was allocated. The Third Critique by contrast has explained how human cognition - with respect not to bare object-determination but to the form of the world - implicates by its very nature a correlative conception of a mode of non-human cognition. The principle of systematicity or purposiveness, which is what determines this form, ${ }^{40}$ is implicated at the root of understanding: empirical laws and even the formation of empirical concepts demand nature's systematicity - the basic function of conceptualizing intuition requires regulation. The conception of a non-discursive mode of cognition implicated by human cognition is thus employed positively, since without it, we cannot make sense of empirical knowledge in general, let alone of our judgements of organic nature. And this can only mean that non-discursive cognition must be regarded as having real or at any rate extra-logical possibility, a claim not previously available to the Critical philosopher: we know that 'systematic discursive cognition' is equivalent to 'cognition by intuitive intellect', so the objective reality of the former commits us to the integrity of the latter. 
To cognize regulatively is therefore to know in the mode of 'ought', and in accordance with an order of synthesis, the domain which an intuitive intellect knows in the mode of 'is' and in accordance with an order of analysis: seeking knowledge through the application of regulative principles is truth-tracking in the sense that, could we but unite our cognitive powers in the manner of an intuitive intellect, our regulative principles would become constitutive. So the principles must be reckoned to have objectivity, of some indeterminate species; however we put it exactly, we have got beyond the standard, merely heuristic view of regulativity that allows itself to be extracted from the First Critique.

Kant's implicit acknowledgement of this 'new objectivity' is evidenced in the further move that he makes in $\$ 78$ of the Dialectic of Teleological Judgement, the introduction of a unitary supersensible ground of mechanism and teleology. The earlier part of his solution to the antinomy of mechanism and teleology - the conversion of constitutive principles into regulative maxims tells us how formal contradiction can be avoided. And there is no practical problem in jointly pursuing mechanistic and teleological lines of research: both can proceed unhindered. But what is also demanded, Kant tells us in $§ 78$, is 'the unification [Vereinigung] of the two principles', 'the unifiability [Vereinbarkeit] of both in the judging of nature in accordance with them' $(\$ 78,412)$; we must secure 'at least the possibility that both may be objectively unifiable in one principle' ( $\$ 78$, 413). This unification cannot of course rest on a 'ground for the explanation (explication) [Erklärung (Explikation)] of the possibility' of products of nature in accordance with the principles - since we have no insight into the inner productive conditions of natural ends - 'but only on a ground for the elucidation (exposition) of this [Grunde der Erörterung (Exposition) derselben] for the reflecting power of judgement' $(\$ 78,412)$. This weaker 'elucidation' does not go so far as to 'derive from a principle', as does 'explanation': but it does rationalize and justify [berechtigt]. Without it, the two principles 'could not subsist alongside one another in the consideration of nature' $(\S 78,412)$, indeed they would appear to conflict. ${ }^{41}$

The important point here is this. Kant's affirmation that there is still a problem, even when the mechanistic and teleological principles have been recast as imperatives guiding research, makes no sense if their meaning is merely imperatival: in accepting the need to rationalize our double mode of judgement of nature, Kant is therefore accepting that to subscribe to the principles is to take a view, however indeterminate, on 'how things are'.

The crux of the argument is that there is a species of form which nature is required to display which cannot be accounted for in Copernican terms, that is, in terms of our securing the conformity of the object with our mode of cognition - a species of form which cannot be thought to have migrated into objects from our mode of cognition, or to have been injected into them by our acts of constituting objects, and so which must be thought as having its source independent of the 
subject; a source which, the combined analyses of $\$ 76$ and $\S 77$ tell us, must be positively conceived in terms of a creative intuitive understanding. And at one point Kant comes close to saying exactly this. He affirms in $\$ 72$ that organized natural beings are to be conceived as natural ends and that as such they contain a 'hint' of reason: 'It must therefore be a certain presentiment [Ahnung] of our reason, or a hint as it were given to us by nature, that we could by means of that concept of final causes step beyond nature' (5:390). (See also $\$ 70$ : There are 'particular experiences [of natural organisms] that bring reason into play in order to conduct the judging of corporeal nature [durch besondere Erfahrungen veranlaßt wird, welche die Vernunft ins Spiel bringen]' (5:386).) Here, therefore, Kant affirms that the heterogeneity of organic beings with inorganic nature is in some manner given to us: we see that certain objects do not fit into Nature conceived mechanically and that they accordingly intimate an origin outside it.

It is consequently tempting to suppose that Kant hereby revokes his claim in the First Critique that reason 'is never in immediate relation to an object' (A643/B671). And this might lead us to ask if the argument could not have been constructed on the basis of organic nature instead of nature's systematicity. To so would however put more weight on the concept of organism than Kant is willing to allow. Kant affirms only that organic life elicits our employment of an idea, not that we cognize natural objects as having the form of reason: it is beyond us to determine whether plants and animals really are formed internally as we think of them (in the same way, objects judged beautiful are ones to which we respond with a free play of imagination and understanding; whether they really are inherently distinguished in their form is not known and not affirmed by Kant). The 'hint of reason' in organic phenomena is both more and less than the systematic structure that we uncover in nature in general by way of the understanding: it is more, in so far as it directly and explicitly intimates a supersensible ground for the object, and it is less, in so far as it is not similarly present in the empirical form of the object - as Kant says in the Appendix of the First Critique, the relation of a sensible schema to an idea of reason can only be one of analogy. ${ }^{42}$ Since we can make no firm claims in their regard, it would consequently be unadvisable to attempt to argue out to knowledge of the noumenal via natural organisms, for they are given only as suggesting ideas of reason, in the manner of analogons, not as embodying them. In short, we know that nature must be systematic, but we cannot know, in the same robust sense, that nature contains objects having the form of reason. Systematicity in nature is therefore on a stronger, because strictly transcendental, footing than organic nature.

It may be worried that to commit Kant to claims (4) and (5) is to lead him into contradiction with his limits of knowledge thesis. If we know nature to be systematic - however it may be that we are obliged to express this knowledge in imperatival form - do we not thereby know something that transcendental idealism says we cannot know? 
It is true that a new grade of realism in cognition has been achieved, but not that we know anything transcendent as it is in itself, i.e. in its transcendentally real essence. What we know is strictly that there is a transcendent ground of the non-sensible form of appearances (what Kant calls in his Inaugural Dissertation 'the form of a world ${ }^{133}$ ), and since this form is not sensible, we are entitled to suppose that the systematic form exhibited in appearances (from which it cannot be abstracted, and which can never be cognized as a totality) is isomorphic with the (form of the) ground. The structure of the ground is cognized only qua its realization or expression in the world as appearance. This is a weak, analogical-formal cognition of a sort that ought not to trouble any Kantian.

It should also be pointed out that no violation or suspension of the Copernican principle that objects are to be regarded as conforming with our mode of cognition is involved. The element in our mode of cognition to which the systematicity of nature conforms is reason, or reflective judgement informed by ideas of reason. It is true that 'conformity' here does not have the (Copernican) character of active determination-of-the-object-by-the-subject, but nor is the agreement of cognition and object arrived at by purely passive (pre-Copernican) determination of the subject, since it discloses itself to us only in and through the spontaneous syntheses of the understanding. Even in the case of the natural organism - as per the 'Ahnung' quotation above nothing is strictly forced on the subject: the relevant idea of reason is elicited, ins Spiel gebracht (the object cues our spontaneity, as in the judgement of taste).

To all of this it may be objected that it remains the case that for Kant what holds up the assumption of nature's systematicity is still (merely) our cognitive needs - our need for empirical law and empirical concepts, and our reason's telos of systematic unity. This is the bottom line. So all of Kant's meta-critical reflections must be as much of an 'as if' as the regulativity of the First Critique. No change of status, no realism of the regulative, can result.

It can be agreed that in one sense a non-subjective conception of the regulative is ruled out if non-subjective means 'grounded in a positive cognition of how things are independently of our mode of cognition'. By virtue of their dependence on the peculiarities of our mode of cognition, regulative representations cannot be representations of things in themselves. What is also true is that Kant's own meta-critical representation of the difference between, and the respective characteristics of, discursive and intuitive understanding is itself conditioned by the discursivity of our intellects. It is for this reason that we represent discursive cognition in positive terms but the intuitive intellect in negative terms (Kant's meta-critical representation of the distinction is asymmetrical: we do not represent it in the terms in which it would be presented by an intuitive intellect). But it is not subjective in the (Neiman's) sense of not 'tell[ing] us about the world at all but [just] how we are to behave'. There is as much justification for saying that the concept of a cognitive need is 
reinterpreted by Kant in a way that implicates objectivity, as there is for saying that the principles of reflective judgement remain subjective.

My claim, I hope it is clear, is not that the non-subjective construal belongs to the letter of Kant's text but that it represents the implicit . It explains, for one thing, the insertion of $\S \S 76-77$ into the argument of the Dialectic of Teleological Judgement, which otherwise is in danger of turning no wheels. Second, it makes possible a connection with morality which would otherwise not be forthcoming: only if the regulative governance of nature has objective significance is it necessary to affirm a supersensible ground of nature, that can then be yoked to the supersensible of practicomoral cognition (allowing the objective reality of the Fact of Reason to lend its weight to natural teleology). Third, and connectedly, it helps Kant return robust answers to various pressing questions: it deflects the global subjectivism charge coming from Jacobi, and it makes Kant's (embattled) postulates of pure practical reason more credible: if regulative principles in theoretical reason are already objectivity-implicating, then practical cognition finds itself with a regulative partner in the theoretical sphere, and the moral theology involves less of a discontinuity with theoretical reason. It thus responds to the charge that, having crippled theoretical reason, Kant cannot consistently resurrect it in the practical sphere. In the same connection - looking ahead a few years - it assists Kant in answering the charge of paradox levelled by Hegel in the 'moral worldview' section of the Phenomenology. ${ }^{44}$

Here is a passage from the First Introduction to the Third Critique which allows us to pinpoint where Kant's idealism stops and Schelling's begins:

[i] Now it is clear that the reflecting power of judgment, given its nature, could not undertake to classify the whole of nature according to its empirical differences if it did not presuppose that [ii] nature itself specifies its transcendental laws [die Natur spezifiziere selbst ihre transzendentale Gesetze] in accordance with some sort of principle. [iii] Now this principle can be none other than that of the suitability for the capacity of the power of judgment itself for finding in the immeasurable multiplicity of things in accordance with possible empirical laws sufficient kinship among them to enable them to be brought under empirical concepts (classes) and these in turn under more general laws (higher genera) and thus for an empirical system of nature to be reached [...] The special principle of the power of judgment is thus: Nature specifies its general laws into empirical ones, in accordance with the form of a logical system, in behalf of the power of judgment [Das eigentümliche Prinzip der Urteilskraft ist also: die Natur spezifiziert ihre allgemeine Gesetze zu empirischen, gemäß der Form eines logischen Systems, zum Behuf der Urteilskraft.]

(First Introduction, Sect. V; 20:215-216) 
This passage - when read in retrospect from the standpoint of Schelling and Hegel - appears to be on the cusp of absolute idealism. Kant [i] begins with the need of our power of judgement to classify nature, [ii] advances to the idea that Nature specifies itself, as it were taking the side of the object and granting it autonomy; but then [iii] restores autonomy to the power of judgement, which is said to determine Nature to specify itself. The three part movement has us travel out of subjectivity for an instant before being restored to it: we come full circle, and subjective idealism remains undisturbed. But there is a clear point at which a different direction could have been taken: it can be denied, in [iii], that 'this principle [of Nature's specification] can be none other than' a principle that relates to our judgement. The principle in question can instead be one that relates Nature to itself - the principle in accordance with which Spinoza's substance determines its modes.

The Kantian may object that to pursue this route is to forget the epistemological task: Nature can specify itself all it likes, but whatever it does is of no use unless it ends up meeting the needs of our power of judgement. This is of course true - the principle required by our power of judgement must make reference to that power - but it does not follow that it must consist only in purposivity for the power of judgement, i.e., that there is nothing more to Nature's principle than its function for judgement (as Kant's 'zum Behuf der Urteilskraft' implies). For the further possibility is that Nature specifies itself on behalf of itself, and that in so doing it brings it about that the purposes of judgement are fulfilled.

This makes sense - and the connection between Nature's self-satisfaction, and its satisfaction of our cognitive needs, will be non-accidental - only if judgement can think of itself as in some way within nature, as opposed to being external to it in pure transcendental fashion. But this too is a conception licensed by $\S 77$, which allows us to represent the subject of discursive understanding as ontologically downstream from the intuitive understanding: as finite entities, we as subjects of cognition figure as objects within its domain. To be sure, more is needed, but a basis has been supplied for thinking of the needs of judgement as truth-tracking. This move has furthermore a precedent in Kant's extrapolation of an order of being from an order of cognition, a ratio essendi into a ratio cognoscendi, in the Fact of Reason argument of the Second Critique. ${ }^{45}$ Whether the projected broader absorption of epistemology into ontology is well-advised - and here the Kantian will again raise objections, in particular concerning the way in which this considerably more complex epistemological story appears to be lending hostages to skeptical fortune - is another question, which depends on how the account can be developed: absolute idealism must show itself to be capable of meeting the challenge of skepticism at least as effectively as Kantian idealism, ${ }^{46}$ and to possess additional philosophical advantages. But already we can see where some of these advantages may be argued to lie: by relocating epistemology on an ontological plane in the way 
proposed, epistemology is able to loop back on itself via the theory of teleology, and the relation of knowledge is shown to be homologous with (perhaps even to be a species of) the type of relation under which objects in Nature must at the highest level be thought to fall, namely relations of purposivity. Claims to knowledge, validated at a first stage from the immanent standpoint of thought by transcendental logic, are then revalidated from the outside, by the conception of reality that opens up at a second stage of transcendental reflection.

Let us return to the contrast drawn at the beginning. If what I have argued is on the right track, then the German Idealist development should be regarded, not as discarding Kant's notion of regulativity, but as following through on it, pushing the conception of regulativity implicit in the Third Critique to its proper, explicit conclusion. The parting of ways of German Idealism and Classical Pragmatism, it follows, is not in the first instance a matter of choosing one of the constitutive and the regulative over the other. The regulative turn made by James is a development within Pragmatism and not definitive of it. What separates the two developments at their historical root is instead their attitude to apriority: Peirce's ab initio commitment to exclusively a posteriori grounds of knowledge precludes his taking the path to objective idealism opened up by $\$ \S 76-77$. Among the many systematic questions we are left with is that of whether Peirce, following an $a$ posteriori path, succeeds in making the transition from the purposivity of human cognition to a conception of purposivity as a wholly general ontological structure. ${ }^{47}$

\footnotetext{
${ }^{1}$ References are to Collected Papers of Charles Sanders Peirce, 8 vols., ed. Charles Hartshorne, Paul Weiss, and Arthur W. Burks (Cambridge, MA: Harvard University Press, 1931-58).

${ }^{2}$ Some interesting complexities in Peirce's account of the structure of knowledge may be noted. Synechism, most often presented as if it were a first-order material hypothesis concerning the universe, is in this context (CP 6.173) treated as a logical correlate of the pragmatic approach to enquiry. Abduction is for Peirce at once a type of reasoning and a 'primary hypothesis' to the effect that 'the human mind is akin to the truth' (CP 7.220), and also a quasi-instinctive disposition the abandonment of which would be senseless. The hope of finding the world explicable is regarded as, on the one hand, not itself equivalent to the postulate that all facts have explanations but rather as that which, in the manner of a disposition, 'animates' hypothesis-formation in general, and on the other hand, as 'a fundamental and primary abduction, a hypothesis' (CP 7.219). That the grounds of knowledge should have this character - its layers melting into one another rather than holding themselves distinct in the manner of Kant's principles - is itself a properly Peircian implication. ${ }^{3}$ E.g., Pragmatism: A New Name for Some Old Ways of Thinking (London: Longmans, Green, \& Co., 1907), Lecture 6.

${ }^{4}$ One exceptional passage, from a very early work, in which Schelling employs the constitutive/regulative distinction will be cited later: see note 40. But the context is one in which Schelling is setting out a path from Kant to absolute idealism.

${ }^{5}$ See the summary of results in F. W. J. Schelling, First Outline of a System of the Philosophy of Nature (1799), trans. Keith R. Peterson (Albany, NY: State University of New York Press, 2004), p. 105.
} 
${ }^{6}$ See the Introduction to Schelling's Ideas for a Philosophy of Nature (1797), trans. Errol E. Harris and Peter Heath (Cambridge: Cambridge University Press, 1988), pp. 30-42. Schelling argues (pp. 34-35) that Kant's strategy of attributing our teleological understanding of nature to the peculiarity of our finite intellects does not allow us to dispense with the hypothesis of a pre-established harmony of our minds nature with our minds and so makes no advance.

${ }^{7}$ G. W. F. Hegel, The Science of Logic (1812-16), trans. A. V. Miller (Atlantic Highlands, NJ: Humanities Press International, 1989), p. 590.

${ }^{8}$ Hegel, Faith and Knowledge (1802), trans. Walter Cerf and H. S. Harris (Albany, NY: State University of New York Press, 1977), p. 80: 'Reason is raised above the sphere of the intellect's relative identity, to be sure, and this negative character would allow us to conceive of it as absolute identity. But it was raised above intellect only to let the speculative Idea - which came out most vividly in imagination and had already been degraded as intellect - finally sink down completely to formal identity. Kant is quite correct in making this empty unity a merely regulative and not a constitutive principle - for how could something that is utterly without content constitute anything?' ${ }^{9}$ The Science of Logic, pp. 404-405.

${ }^{10}$ Frederick Beiser, German Idealism: The Struggle Against Subjectivism, 1781-1801 (Cambridge, MA: Harvard University Press, 2002), pp. 217-218, 237-239. Schelling 'departs from Fichte' in so far as he 'gives the idea of the absolute not a regulative but a constitutive status'; the absolute ego is for Fichte 'an ideal for action' but for Schelling 'an existing reality' (p. 473). An earlier regulative construal of Fichte is in Tom Rockmore, Hegel's Circular Epistemology (Bloomington, IN: Indiana University Press, 1986), pp. 41-43.

${ }^{11}$ Fichte's references to the regulative are scarce and concern chiefly the natural sciences. Two passages that do however support the regulative reading are in the 1793-94 'Praktische Philosophie' (Gesamtausgabe, ed. Reinhard Lauth et. al. (Stuttgart-Bad Cannstatt: Frommann-Holzboog, 1964ff), II.3, 179-266), p. 238, and the 1795 Outline of the Distinctive Character of the WL with Respect to the Theoretical Faculty (in Early Philosophical Writings, trans. and ed. Daniel Breazeale (Ithaca, N.Y.: Cornell University Press, 1988), pp. 243-306), p. 246.

12 This I have argued in 'The Status of the Wissenschaftslehre: Transcendental and Ontological Grounds in Fichte', Internationales Jahrbuch des Deutschen Idealismus - Metaphysik im

Deutschen Idealismus 5, 2007, 90-125.

${ }^{13}$ See Paul Franks, All or Nothing: Systematicity, Transcendental Arguments, and Skepticism in German Idealism (Cambridge, MA: Harvard University Press, 2005), Ch. 4.

${ }^{14} \mathrm{My}$ thought is that although regulativity itself has a low profile in German Idealism, the issues which it raises are taken up by the German Idealists, in relation to the concept of a postulate. For the beginnings of such an account, see my 'Kant's Practical Postulates and the Limits of the Critical System', Bulletin of the Hegel Society of Great Britain, 63, 2011, 187-215.

${ }^{15}$ James, Essays on Radical Empiricism (London: Longmans, Green, and Co., 1912), pp. 159-160. See also p. 241: the inadmissibility of any element not directly experienced 'is only a methodological postulate, not a conclusion supposed to flow from the intrinsic absurdity of transempirical objects'. James' regulativism is clear from his early 'Remarks on Spencer's Definition of Mind as Correspondence', The Journal of Speculative Philosophy, 12, 1878, pp. 1-18.

${ }^{16}$ James, Pragmatism, p. 205.

${ }^{17}$ Even at this stage, it should be noted, Peirce describes the conditions in question as 'facts', i.e. regards them as candidates for truth.

${ }^{18}$ Peirce disparages 'transcendental apothecaries' as epistemically ineffective: 'A transcendentalist would claim that it is an indispensable "presupposition" that there is an ascertainable true answer to every intelligible question. I used to talk like that, myself; for when I was a babe in philosophy my bottle was filled from the udders of Kant. But by this time I have come to want something more substantial' (CP 2.113).

${ }^{19}$ See also CP 5.160: 'But the saving truth is that there is a Thirdness in experience [...] If this were not the case, there could be no such thing as logical goodness or badness.' 
${ }^{20}$ A Commentary to Kant's 'Critique of Pure Reason' (London: Macmillan, 1918), p. 500. Kemp Smith's view is that two views of reason are present in the Critique, an older view according to which reason is 'merely understanding in its transcendent employment' and a later view of it 'as a distinct faculty, yielding concepts with a positive and indispensable function' (p. 439): but even in the latter, positive respect, reason's function consists only in 'limiting and directing the understanding', on the one hand expressing 'Ideal standards' of knowledge, and on the other prescribing 'problems which the understanding is called upon to solve' (p. 426).

${ }^{21}$ Robert E. Butts, Kant and the Double Government Methodology (Dordrecht: Reidel, 1984), pp. $11,211,215$.

${ }^{22}$ The Unity of Reason: Rereading Kant (Oxford: Oxford University Press, 1994), pp. 13, 34, 45, 69.

${ }^{23}$ Neiman, The Unity of Reason, pp. 90-91.

24 The problem is nicely described by Butts, who thinks that it has only an aesthetic answer: 'One cannot underestimate the importance of this problem for Kant. His critique of pure reason has rendered reason impotent as an organ productive of constitutive knowledge; there are no objects for reason to know, and hence no legitimate truth claims for reason to father. Reason does not produce (empirical) knowledge; as the form of logic, reason orders what the understanding knows. Why give reason this privileged role? Why must the set of natural laws or of empirical concepts (each one of which is itself a rule, and hence a law stated as a set of conditionals) be uniquely specifiable as a system? Why not take the laws as we find them, and perhaps conclude that disorder and irreducible multiplicity are characteristic of the set of empirical discoveries? Kant's full answer, one that will be investigated in detail in the following chapters, seems to me to come simply to this: the urge to systematization obtains whatever objectivity it possesses from the subjectively valid teleological constraint that is put upon thought by the necessity of regarding nature at large as a work of art, as a construct satisfying demands of reason that are demands of a blueprint requiring to be realized. It is because we make nature that we require it to satisfy certain aims; the aims are determinative of the need for system. The justification of the principles of the logic of system rests on aesthetic grounds. But this is not the answer to his problem that Kant gives in the 1st Critique. There, he only hints at what is to come later' (Kant and the Double Government Methodology, p. 220).

${ }^{25}$ Hans Vaihinger, The Philosophy of 'As If': A System of the Theoretical, Practical and Religious Fictions of Mankind (1911), trans. C. K. Ogden (London: Routledge and Kegan Paul, 1924).

${ }^{26}$ See in particular the essays in Henry E. Allison, Kant's Theory of Taste: A Reading of the Critique of Aesthetic Judgment (Cambridge: Cambridge University Press, 2001), Pt. I, and in Paul Guyer, Kant's System of Nature and Freedom: Selected Essays (Oxford: Oxford University Press, 2005), Pt. I.

${ }^{27}$ See esp. $\$ \$ 70-72$.

${ }^{28}$ Critique of the Power of Judgement, ed. Paul Guyer, trans. Paul Guyer and Eric Matthews (Cambridge: Cambridge University Press, 2002).

${ }^{29}$ In fact this contrast needs refinement, for Kant's position in the 'The Regulative Employment of the Ideas of Pure Reason' is far from straightforward. More detailed exegesis is required, but the point is sufficiently important for the case I am making to deserve a brief summary. In the first few pages, from A642/B671 to A650/B678, Kant talks generally about the transcendental ideas treated earlier in the Dialectic and makes two points: that they are incapable of objectivity or constitutive employment, and that reason has a positive function in relation to the understanding. (This part of the discussion is continuous with Sections 8 and 9 of the Antinomy: A516-517/B544-545.) The second point is explained in terms of reason's provision of an 'idea' or 'concept of an object' distinct from the transcendental ideas of the Dialectic, namely 'the form of a whole of cognition, which precedes the determinate cognition of the parts' (A645-646/B673-674). The positive function of this newly introduced idea is defined in at least six different ways. Its employment stands under the same restrictions as the transcendental ideas: it is 'not properly constitutive' (A647/B675), though it is liable to be misunderstood as such; systematic unity is 'a logical principle', 'subjectively and 
logically necessary, as method', and not 'objectively necessary' (A648/B676). As Kant also puts it: the licensed use of reason in systematizing natural knowledge is 'hypothetical' and not 'apodictic' (A646-647/B674-675), and without claim to 'objective reality' (A650/B678). Its hypotheticality consists in its postulation of the universality of a rule, without the epistemic possibility of determining the rule as strictly universal.

The paragraph which upsets this picture is at A651/B679: 'In fact it cannot even be seen how there could be a logical principle of rational unity among rules unless a transcendental principle is presupposed, through which such a systematic unity, as pertaining to the object itself, is assumed $a$ priori as necessary [...] For the law of reason to seek unity is necessary, since without it we would have no reason, and without that, no coherent use of the understanding, and, lacking that, no sufficient mark of empirical truth; thus in regard to the latter we simply have to presuppose the systematic unity of nature as objectively valid and necessary.' The elevation of the relevant principles (maxims of reason, as Kant will later rename them) to transcendentality is confirmed at several further places: A654/B682, A656/B684, A660/B688, A663/B691.

The limitations of the discussion of nature's systematicity in the First Critique, from the standpoint of the Third Critique, are therefore arguably more a matter of definiteness of presentation than of substance. The complexity of the Regulative Employment section is due to the fact that no less than three different cases (different types of principle or employment of reason) are under discussion:

(1) The transcendental ideas of soul, world and God (concepts of totality and unconditioned). These are merely subjectively necessary, without objective validity, logical and not transcendental, and fit for regulative but not constitutive employment. (Their regulative potential is intimated in the Antinomy, Section 9, and will later be made explicit in the 'transcendental deduction of all ideas of speculative reason [...] as regulative principles', A671/B699.)

(2) The principles of systematicity in cognition associated with reason's idea of a whole of knowledge. These too are merely subjectively necessary, without objective validity, logical and not transcendental, and fit for regulative but not constitutive employment.

(3) The principles of systematicity in nature (homogeneity, specification, and continuity, A658/B686; manifoldness, affinity, and continuity, A662/B690). These characterize nature as regards its form or structure. They are objectively as well as subjectively necessary, have objective (albeit 'indeterminate') validity, and are not merely logical but transcendental. Their employment is regulative (A662/B690). Are they however also in any sense constitutive? They cannot be employed constitutively, on account of their indeterminacy, but they are synthetic a priori and 'serve as rules for possible experience' (A663/B691).

What is liable to cause confusion is that Kant in his exposition passes directly from (2) to (3). This is understandable, since his claim is precisely that they map onto one another: what he seeks to emphasize is the correspondence of (3) (= established principles of natural science and characterizations of nature) with (2) (= Kant's Critical innovation). It is however at the same time reasonably clear that he maintains a distinction of (2) from (3): the passage quoted above from A651/B679 and its associates at A654/B682, A656/B684, A660/B688, and A663/B691, all imply that to each logical principle there corresponds a distinct transcendental principle.

Obviously the principles that concern Kant in the Third Critique belong to (3). The point to be emphasized is this. Kant's presentation of (3) in the First Critique is less clearly 'objectivist' than it is in the Third Critique because in the former he approaches them from the angle of reason, not from that of the needs of the understanding. It $i$ s therefore maintained in the First Critique, but only obscurely, that (3) are necessary for experience as such, and not just for its theoretical elaboration. ${ }^{30}$ The corresponding quotations from the published Introduction are in Section IV, 179-180, and Section V, 183-184. 
${ }^{31}$ See the works of Allison and Guyer cited in note 26, and James R. O'Shea, ' The Needs of Understanding: Kant on Empirical Laws and Regulative Ideals', International Journal of Philosophical Studies, 5, 1997, 216-254.

${ }^{32}$ See, e.g., Metaphysik Mrongrovius (1782-83), 29:747; Lectures on Metaphysics, trans. and ed. Karl Ameriks and Steve Naragon (Cambridge: Cambridge University Press, 1997), p. 109.

${ }^{33}$ Introduction to the Outline of a System of the Philosophy of Nature, pp. 202, 227, 232.

${ }^{34}$ Critique of Pure Reason, trans. and ed. Paul Guyer and Allen Wood (Cambridge: Cambridge University Press, 1998).

35 Though it is explicit in Kant's Jäsche Logic, §83, which ascribes to reflective judgement the principle that where particulars 'agree in one' (where there is something that 'belongs to the many'), there must be 'a common ground'; Lectures on Logic, trans. and ed. J. Michael Young (Cambridge: Cambridge University Press, 1992), p. 626.

${ }^{36}$ See A113-114.

${ }^{37}$ This model of identity across the is/ought distinction - which allows us to ascribe a kind of truth to an imperative - is of course familiar from Kant's treatment of the moral law as both the law of a holy will and the practical law of an imperfect will.

38 '[S]ystematic unity (as mere idea) is, however, only a projected unity, which one must regard not as given in itself, but only as a problem' (A647/B675).

${ }^{39}$ Schelling, Of the I as Principle of Philosophy, or on the Unconditional in Human Knowledge (1795), in The Unconditional in Human Knowledge: Four Early Essays 1794-1796, trans. and ed. Fritz Marti (Lewisburg: Bucknell University Press, 1980), p. 127.

${ }^{40}$ Kant equates the two: 'lawfulness of the contingent is called purposiveness' $(\$ 76,404)$.

${ }^{41} \S 78,413$ : 'apparent conflict [scheinbaren Widerstreit]'.

42 A665/B693.

${ }^{43}$ See Inaugural Dissertation, esp. $\$ 13$ and $§ 16 ;$ Theoretical Philosophy, 1755-1770, trans. David Walford, in collaboration with Ralf Meerbote (Cambridge: Cambridge University Press, 1992), pp. 391 and 401. The matter of the world is the all-encompassing set of coordinated contingent substances $(\S 3,2: 389)$; its form is the ground of the possibility of their causal coordination $(\S 3$, 2:390).

${ }^{44}$ Hegel's criticism is that, since Kant holds that the ground of all value exists solely in the form of the moral 'Ought', which he requires us to think of as postulated beyond reality, when we ask, as we must, What kind of reality does the moral Ought itself have?, Kant's answer cannot avoid contradiction. If the ground of the Ought exists in the same way as the ground of nature's systematicity, it is less obvious that Kant's conception of 'postulated reality' is paradoxical. ${ }^{45}$ Preface, 5:4n.

${ }^{46}$ The force of Schelling's reply to the skeptic cannot be evaluated here, but his claim is that Nature at once makes our cognition and its own self-cognition possible.

${ }^{47}$ I am very grateful for comments on earlier drafts given at the Johann Wolfgang GoetheUniversität Frankfurt am Main, the University of Tübingen, Leipzig University, and the University of Turku, and and in particular to Paul Franks, Gabriele Gava, Olli Koistinen, Sebastian Rödl, Ulrich Schlösser, and Bob Stern. 